\title{
A tripeptide-based self-shrinking hydrogel for waste-water treatment: removal of toxic organic dyes and lead (Pb2+) ions
}

Article

Accepted Version

Basak, S., Nandi, N., Paul, S., Hamley, I. and Banerjee, A. (2017) A tripeptide-based self-shrinking hydrogel for wastewater treatment: removal of toxic organic dyes and lead $(\mathrm{Pb} 2+)$ ions. Chemical Communications, 53 (43). pp. 5910-5913. ISSN 1359-7345 doi: https://doi.org/10.1039/C7CC01774J Available at https://centaur.reading.ac.uk/70402/

It is advisable to refer to the publisher's version if you intend to cite from the work. See Guidance on citing.

To link to this article DOI: http://dx.doi.org/10.1039/C7CC01774J

Publisher: The Royal Society of Chemistry

All outputs in CentAUR are protected by Intellectual Property Rights law, including copyright law. Copyright and IPR is retained by the creators or other copyright holders. Terms and conditions for use of this material are defined in the End User Agreement.

www.reading.ac.uk/centaur 
Central Archive at the University of Reading

Reading's research outputs online 


\section{Journal Name}

\section{COMMUNICATION}

\section{A Tripeptide-based Self-Shrinking Hydrogel for Waste-Water Treatment: Removal of Toxic Organic Dyes and Lead $\left(\mathrm{Pb}^{2+}\right)$ lons}

Received 00th January 20xx Accepted 00th January 20xx

DOI: $10.1039 / x 0 x \times 00000 x$

\author{
ShibajiBasak, ${ }^{a}$ NibeditaNandi, ${ }^{a}$ SubirPaul, ${ }^{\mathrm{a}}$ Ian Hamley, ${ }^{\mathrm{b}}$ and ArindamBanerjee ${ }^{\mathrm{a}, *}$
}

www.rsc.org/

A triphenylalanine-based superhydrogel shows automatic syneresis (self-compressing property) with time and this selfshrinking behavior has been successfully utilized to remove toxic lead ions and organic dyes from waste-water efficiently with the ability to re-use multiple times.

Supramolecular hydrogels ${ }^{1}$ composed of low molecular weight gelators (LMWGs) ref are a rapidly expanding area of recent research due to their wide range of applications including controlled release of biologically active compounds and drugs, $^{2 e-g}$ cell culture and tissue engineering, ${ }^{\text {ref }}$ sensing, ${ }^{4 a-b}$ nano-particle and nano-cluster synthesis, ${ }^{\text {ref }}$ catalysis ${ }^{6 c-d}$ and other purposes. Peptides are particularly useful candidates to study self-assembly and gelation as these molecules are biocompatible and biodegradable in nature ${ }^{7 e f}$ as well as incorporating a diversity of amino acids which leads to versatility in the control of peptide sequence. Among the peptide gels so far reported it was found that hydrophobic amino acids especially phenylalanine have an important role in the gelation process. ${ }^{8}$ However, use of phenylalanine has a limitation as it reduces the solubility of the gelator molecule in aqueous medium. ${ }^{9}$ The hydrophobicity of gelators often leads to 'syneresis'10, a phenomenon involving the expulsion of the gelling solvent from the gel phase and ultimately macroscopic contraction of the gel, which occurs within several hours. This phenomenon has been mostly observed for many sol-gel based polymeric systems. ${ }^{11}$ In contrast, there are only a few reports on stimuli-responsive syneresis in supramolecular hydro- or organogels driven by external stimuli including $\mathrm{pH}^{12 \mathrm{a}}$ metal ion, ${ }^{12 b}$ photo-irradiation, ${ }^{12 c, d}$ mechanical pressure ${ }^{12 \mathrm{e}}$ or in the presence of external chemicals. ${ }^{12 f}$ So there is a need to explore

a. Department of Biological Chemistry, Indian Association for the Cultivation of Science, Jadavpur, Kolkata, 700032 (India) Fax: (+ 91) 33-2473-2805, E-mail: bcab@iacs.res.in.

b. Department of Chemistry, University of Reading, Whiteknights, Reading, RG6, 6AD, UK.

Electronic Supplementary Information (ESI) available: [Experimental section, Instrumentation, Synthetic procedures, NMR, HRMS, Spectroscopic studies, FTIR, XRD, SAXS, Rheological studies.] See DOI: 10.1039/x0xx00000x supramolecular hydrogels that show shrinking property without any external stimulus. In the course of our investigation to study the self-assembly and gelation behavior of self-assembling peptide-based molecules, a tripeptide-based amphiphile has been discovered to form a hydrogel at $\mathrm{pH} 7.4$ and it has been found to exhibit a remarkable self-shrinking property with time (Fig. 1a, b).
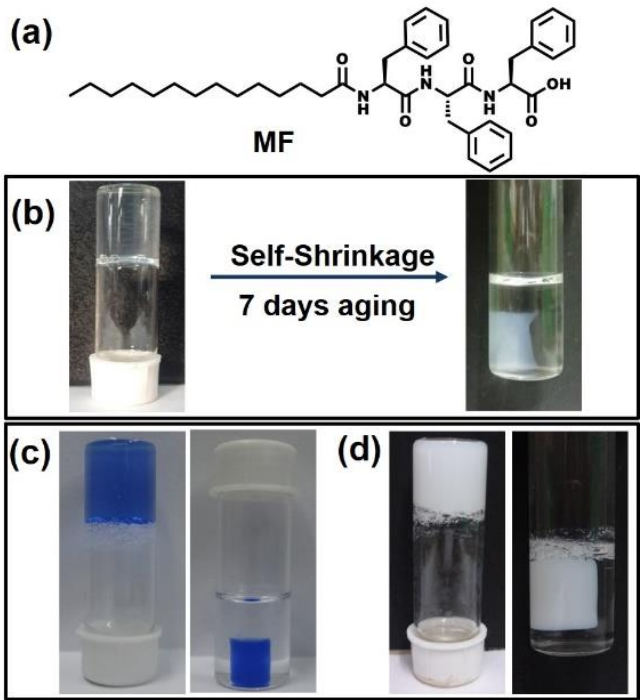

Fig. 1 (a) The chemical structure of the amphiphile MF. (b) Transparent fresh hydrogel obtained from MF (at $1.5 \mathrm{mM}$ concentration) and 7 day aged opaque gel upon syneresis. (c) Photographs of dye (Brilliant blue) containing hydrogel before and after syneresis. (d) Photographs of $\mathrm{Pb}^{2+}$ ion containing hydrogel before and after syneresis.

Water pollution caused by toxic organic dyes and leaching of heavy metal ions including lead $(\mathrm{Pb})$, cadmium $(\mathrm{Cd})$, mercury $(\mathrm{Hg})$ and others from industrial waste is a great threat to modern society. ${ }^{\text {ref }}$ The dye effluents have a negative impact on the immune system, reproductive systems as well as they exhibit potential geno-toxicity and cardio-toxicity. ${ }^{13}$ On the other hand, lead has a deleterious effect on human health including renal, reproductive, central nervous and hematopoietic systems through the enhancement of oxidative 
stress. ${ }^{14}$ There is thus a prime interest for the development and analysis of environmentally friendly materials to protect the environment by removing toxic pollutants from contaminated water. There are some methods to remove pollutants from waste-water using functionalized CNTs, photocatalysis, reverse osmosis and others. ${ }^{15}$ In this connection, supramolecular hydrogels are wonderful materials due to their highly porous fibrous network structure and large surface areas in the gel matrix to trap the toxic pollutants. ${ }^{16}$ There are a few examples of polymer based and graphene containing hydrogels for the removal of lead ions from waste-water. ${ }^{17}$ However, none of these above mentioned hydrogels are peptide based and exhibit a self-shrinkage property. Herein, we report a novel triphenylalanine-based hydrogel that can offer an easy and effective way to remove water-soluble pollutants to have clean and safe water upon instant syneresis. In this study, the hydrogel has a good capacity to entrap toxic $\mathrm{Pb}^{2+}$ ions as well as toxic organic dyes (Methylene blue, Brilliant blue) from wastewater (Fig. 1c, d). The scavenging capacity of removing toxins from contaminated water is excellent as an appreciable amount (1995 mg) of $\mathrm{Pb}^{2+}$ ions can be removed per gram of gelator from waste-water. To the best of our knowledge, it is the highest $\mathrm{Pb}^{2+}$ ion absorption capacity by a hydrogel reported so far. ${ }^{17 a}$ Moreover, only a small amount of the gelator is required (less than $1 \mathrm{mg} / \mathrm{mL}$ ) to prepare this superhydrogel and it is recyclable several times to efficiently remove toxic substances from wastewater.

The tripeptide based amphiphilic gelator MF (Fig. 1a) was observed to self-assemble in phosphate buffer at $\mathrm{pH} 7.4$ to form a thermo-reversible, $\mathrm{pH}$ sensitive hydrogel. The gelator molecule MF has three phenylalanine moieties bearing hydrophobic $\pi$-core, thus making the molecule highly hydrophobic in nature. Therefore, it is hard to dissolve the gelator in aqueous medium and it requires 15-20 minutes of heating on a hot plate followed by cooling at room temperature $\left(25^{\circ} \mathrm{C}\right)$ to obtain a transparent hydrogel. The minimum gelation concentration (MGC) was found to be $1.2 \mathrm{mM}(0.08 \% \mathrm{w} / \mathrm{v})$ to form a self-supporting gel. The gel melting temperature $\left(T_{\text {gel }}\right)$ at MGC was found to be $60^{\circ} \mathrm{C}$. The temperature vs. concentration plot (Fig.S1a) of the freshly prepared hydrogel shows very high thermal stability. Interestingly, the $\mathrm{T}_{\text {gel }}$ of hydrogels was noticed to reach even above the boiling point of water above a concentration $2.5 \mathrm{mM}$. Surprisingly, a more interesting feature of volume phase transition - 'syneresis' - was observed for this hydrogel. The hydrogel is started to shrink immediately after its formation followed by the expulsion of water from the gel matrix (Fig. 1b). The freshly prepared gel was transparent in nature, while the aged gel gradually became opaque upon shrinking. The shrinking capacity of the hydrogel was quantitatively evaluated by measuring the volume of the expelled water from the shrunken gel as well as volume of the shrunken gel itself. It was observed that the volume of the expelled water gradually increases with time and after 7 days the volume of the hydrogel contracts to about $75 \%$ of its original volume by releasing about $61.4 \%$ clear water from $2 \mathrm{~mL}$ of hydrogel (1.5 mM) (Fig. S1b). This shrinkage process is thermo-reversible and upon heating a shrunken gel to about 90
${ }^{\circ} \mathrm{C}$ leads to a homogenous solution. A hydrogel is formed again after slow cooling this solution cooling for around 20 minutes to room temperature $\left(25^{\circ} \mathrm{C}\right)$, that again exhibits a self-shrinking property with time. So, this gelator molecule is recyclable in nature.

To investigate whether there is any morphological change associated with the interesting syneresis process, Field Emission Scanning Electron Microscopy (FE-SEM) was carried out for the xerogels obtained from freshly prepared gel and the 7 days aged gel. Fig.2a, b show that both of these xerogels appear to contain well-developed numerous intertwined nano-fibres (average width $25 \mathrm{~nm}$ to $45 \mathrm{~nm}$ ) in their self-assembled states. Comparison between these two images (freshly prepared and 7 days aged gel) indicates that the morphology of the fibrous network does not notably change upon syneresis. It is also reported by other groups ${ }^{\text {ref }}$ that syneresis does not affect the morphology of these hydrogels. (c)
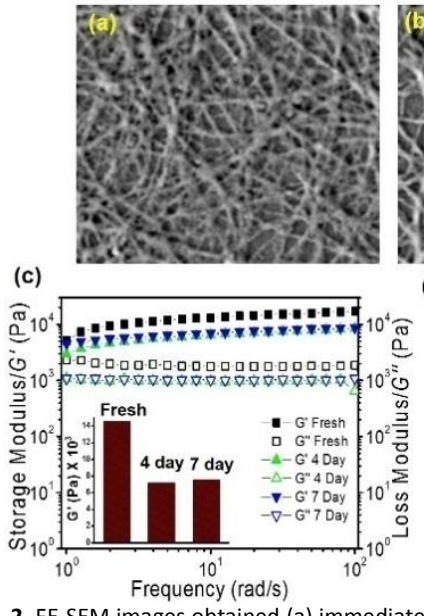

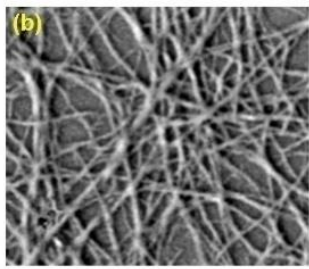

(d)

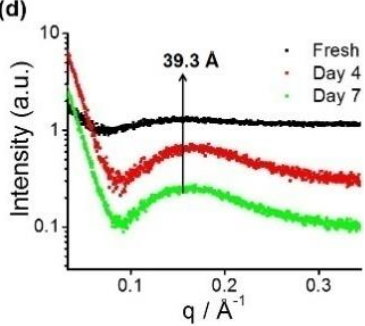

Fig. 2. FE-SEM images obtained (a) immediately after gel formation and (b) after 7 days of syneresis. (c) Modulus Frequency sweep experiment of hydrogels (fresh, 4-day and 7day aged gels) at $2.5 \mathrm{mM}$ concentration. (d) SAXS data obtained from the xerogels (obtained from fresh, 4-day and 7-day aged gels).

To get insight into the mechanical strength and flow behaviour of the hydrogels, rheological experiments were performed for the fresh hydrogel, and 4 day and 7 day aged gels. The frequency sweep experiments (Fig. 2c) suggest that the storage modulus of these hydrogels are very similar and on the order of $10^{3}-10^{4} \mathrm{~Pa}$. In another typical experiment (Fig. S2), for the freshly prepared hydrogel, initially the oscillatory stress storage modulus is higher than loss modulus and at $271 \mathrm{~Pa}$ (yield stress) the storage modulus and loss modulus cross each other. However, for the 4 day and 7 day aged gels the yield stress is $146 \mathrm{~Pa}$. These rheological studies indicate that the stiffness of the freshly prepared gel is more than that of the 4 day and 7 day aged gels and it is clear that syneresis does have a negative effect on the gel strength and the exact reason for that is yet to be explored.

The slow shrinkage of the hydrogel inspired us to look into the detailed packing pattern of the gelator molecules within the hydrogel. In small angle X-ray scattering (SAXS) experiment, a broad peak is observed at $39.3 \AA$, which becomes more pronounced with time as indicated in Fig. 2 d. This length $(39.3$ 
$\AA$ ) is greater than the molecular length of a single gelator molecule (calculated to be $28 \AA$ ), but shorter than double the calculated molecular length, indicating an interdigitated arrangement of the molecules in the gel phase. The SAXS data clearly suggests that this packing arrangement becomes more prominent upon shrinkage of the gel rather than the freshly prepared gel as the peak (39.3 $\AA$ ) is absent in the freshly prepared gel. In the wide angle powder X-ray diffraction (WXRD) pattern of the xerogels (fresh and aged), the appearance of peaks at $2 \theta=19.2^{\circ}(d=4.5 \AA)$ and $2 \theta=22.5^{\circ}(d$ $=3.7 \AA$ ) respectively suggest a $\beta$ - sheet like structure and $\pi-\pi$ stacking of the phenyl rings in the hydrogel states (Fig. S3). Fourier transform infra-red (FTIR) studies were performed to examine the intermolecular arrangement of the molecules in their gel states and the xerogels (obtained from the freshly prepared and 7 day aged gels). The spectra follow a similar pattern as evident form Fig. S4. Peaks at $3416 \mathrm{~cm}^{-1}$ and $3292 \mathrm{~cm}$ 1 are associated with hydrogen bonded and non-hydrogen bonded amide $\mathrm{N}-\mathrm{H}$ stretching respectively and the peak at 1640 $\mathrm{cm}^{-1}$ is due to amide carbonyl group stretching, clearly indicating the presence of an intermolecular hydrogen bonded sheet like extended backbone structure in the gel state (Fig. SXX).

The shrinkage property can be used as an easy method to remove toxic metal ions such as lead. An aliquot $10 \mu \mathrm{L}$ of $66.2 \mathrm{mM}$ solution of lead nitrate $\mathrm{Pb}\left(\mathrm{NO}_{3}\right)_{2}$ was added to the hot solution of amphphile MF at $1.5 \mathrm{mM}$ concentration and the whole solution was sonicated for few seconds. A white precipitate was formed that dispersed homogeneously into the whole solution. After cooling the solution to room temperature a translucent hydrogel was formed. Interestingly, this whitecolored opaque hydrogel containing $\mathrm{Pb}^{2+}$ ions started to shrink within an hour of its formation by expelling clear water (without $\mathrm{Pb}^{2+}$ ions). The separation of white hydrogel leaving behind colourless water indicates that $\mathrm{Pb}^{2+}$ ions get entrapped into the self-compressed hydrogel network (Fig. 1d). The effect of anion was also tested by taking lead perchlorate $\left(\mathrm{Pb}\left(\mathrm{ClO}_{4}\right)_{2}\right)$ as a $\mathrm{Pb}^{2+}$ ion source. However, no significant anion effect was found as $\mathrm{Pb}\left(\mathrm{ClO}_{4}\right)_{2}$ also get separated from the solution (Fig. S5). The whole study can be represented as a schematic diagram as in Fig. S6.

Atomic absorption spectroscopic (AAS) was performed to determine the efficiency of the hydrogel for $\mathrm{Pb}^{2+}$ ion separation. An amount $20 \mu \mathrm{L}$ of the shrinkage gel and $20 \mu \mathrm{L}$ of the expelled water were taken respectively to prepare $20 \mathrm{ml}$ solutions to measure the $\mathrm{Pb}^{2+}$ concentration (ppm). These solutions were stirred for $4 \mathrm{~h}$ at room temperature, followed by filtration. The concentration of the $\mathrm{Pb}^{2+}$ ions in the initial solution was determined through AAS using a standard calibration curve. However, the results are striking as the freshly made hydrogel contains a $\mathrm{Pb}^{2+}$ ion concentration of $2.9285 \mathrm{ppm}$ whereas $\mathrm{Pb}^{2+}$ ion concentration in the expelled water part is $0.0773 \mathrm{ppm}$. This indicates that the $\mathrm{Pb}^{2+}$ ion concentration is negligible in the water phase compared to the aged and shrunken hydrogel as the concentration of $\mathrm{Pb}^{2+}$ ions in the aqueous phase is insignificant (99\%). This performance is better than previous reports as the efficiency and extent of $\mathrm{Pb}^{2+}$ ion removal from water by using our gelator is improved. To the best of our knowledge, this is the first report of a peptide-based supramolecular superhydrogel that shows a fascinating selfcompressing property through the expulsion of water. It also demonstrates the potential usability of this hydrogelator in waste-water treatment by removing toxic heavy metal ions $\left(\mathrm{Pb}^{2+}\right)$ and environmentally harmful organic dyes.
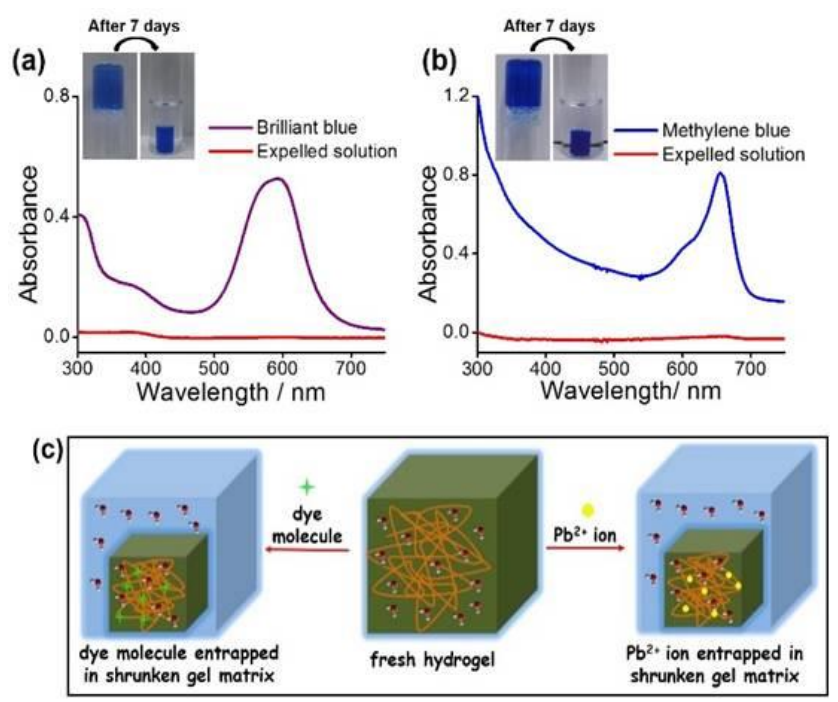

Fig. 3. UV-visible spectra of (a) Brilliant blue and (b) Methylene blue containing gel and the solution after syneresis showing the absence of the corresponding dyes. (c) A schematic representation showing the entrapment of toxic dye molecules and $\mathrm{Pb}^{2+}$ ions within the hydrogel matrix upon syneresis.

For the dye removal study $10 \mu \mathrm{L}$ of a $1 \mathrm{mM}$ solution of Brilliant blue and Methylene blue was added to a $1.5 \mathrm{mM} 2 \mathrm{~mL}$ hydrogel in phosphate buffer respectively. Upon cooling, hydrogels were formed and the dye molecules were trapped in the hydrogel matrix (Fig. 1c). Within $1 \mathrm{hr}$. these hydrogels started to shrink by expelling clear water (Fig. 1c). UV-visible spectroscopy spectra shown in Fig. 3a, b show that a negligible number of the dye molecules are present in the expelled water part compared to the initial concentration of the dye molecules present in the hydrogels. The highest loading capacity for both these dyes is given in the Table S1. The dye removal capacity was found to be remarkably high for both of these tested dyes (99\%). Moreover, removal of all these toxic substances ( $\mathrm{Pb}^{2+}$ and organic dyes) was also tested in a mixture of these three substances and all these substances are removed, leaving behind clear water. This indicates that this tripeptide-based gelator molecule has great potential in future in waste-water treatment. Moreover, the removal of toxic substances ( $\mathrm{Pb}^{2+}$ ions and organic dyes) together in a mixture was also tested and all these substances are sequestered (Fig. S7).

We were curious to know whether $\mathrm{Pb}^{2+}$ ions interact with the gelator peptide or not and to examine this, shrunken and aged gels containing $\mathrm{Pb}^{2+}$ ions were taken out from the vial and were placed in a saturated solution of EDTA-Na 2 . Interestingly, it was found that after 10 hours the white coloured gel was not completely white, the outer portion started to become transparent leaving the middle portion white (Fig. S8). As time elapsed, the gel started to become translucent from its initial 
opaque white state. After 20 hours, only a small portion was white at the middle and the outer portion became translucent gel. After 24 hours, it was completely transformed to a translucent gel. The observation can be due to the leakage of $\mathrm{Pb}^{2+}$ ions from the gel matrix upon complexation with EDTA. So, it can be envisaged that toxic $\mathrm{Pb}^{2+}$ ions are entrapped into the three-dimensional porous network structure of the hydrogel without any complexation with the gelator molecule. The FTIR data also supports this result as there is no change in carboxyl and amide stretching before and after addition of $\mathrm{Pb}^{2+}$ ions into the gel. Thus, $\mathrm{Pb}^{2+}$ ions are physically absorbed within the gel matrix and these ions can be easily removed with a strong complexation with EDTA.

To check reusability, the dye and metal ion-containing shrunken gels were treated with saturated potassium hydrogen sulphate solution which was extracted with ethyl acetate by following the standard methods. ref It was found that the highly water soluble pollutants (dye and metal ions) remain in the aqueous phaseand the gelator molecules go into the organic phase. Thus, the pollutant-free gelator peptide was extracted. As shown in Fig. S9, by using the above stated method, we can use the gelator molecule for a maximum four cycles with only nominal loss of the gelator compound.

In summary, a tripeptide-based potent hydrogelator has been discovered, which forms a super-hydrogel at a very low concentration. This hydrogel exhibits a remarkable timedependent self-shrinking property by expelling water molecules. Moreover, this hydrogel has been successfully utilized for efficient removal of pollutants including toxic heavy metal ions $\left(\mathrm{Pb}^{2+}\right)$ and toxic organic dyes from waste water. The relatively cheap starting materials to synthesize the gelator, the low amount required to form a gel ( $<1 \mathrm{mg}$ to make $1 \mathrm{~mL}$ gel), the higher absorption capacity, and reusability of the gel hold future promise for using this soft material in waste-water management.

N. N and S. P gratefully acknowledge CSIR, New Delhi, India for financial assistance. We acknowledge Rumana Parveen, Department of Organic Chemistry, IACS and Department of Biotechnology (DBT), New Delhi (DBT project number: $\mathrm{BT} / 01 / \mathrm{CEIB} / 11 / \mathrm{V} / 13$ ) for allowing us to use an Anton Paar modular compact rheometer (MCR 102) for rheological measurements.

\section{Notes and references}

1 (a) S. Fleming and R. V. Ulijn,Chem. Soc. Rev., 2014, 43, 8150; (b) Y.Kuang, Y. Gao, J. Shi, H.-C. Lin and B. Xu, Chem. Commun., 2011, 47, 8772-8774; (c) M. T.-Solsona, S. A.-de Castro, J. F. Miravet and B. Escuder,J. Mater. Chem. B, 2014, 2, 6192; (d)A. Baral, S. Basak, K. Basu, A. Dehsorkhi, I. W. Hamley and A. Banerjee,Soft Matter, 2015, 11, 4944; (e) R. G. Weiss, J. Am. Chem. Soc. 2014, 136, 7519; (f) X. Du, J. Zhou, J. Shi and Bing Xu, Chem. Rev. 2015, 115, 13165; (g) J. A. Hutchinson, S. Burholt, I. W. Hamley, j. Pept. Sci, 2017, 23,82.

2 (a) Y. Yamada and J. P. Schneider,Biomacromolecules 2016, 17, 2634; (b) K. Lalitha, Y. S. Prasad, C. U. Maheswari, V. Sridharan, G. John and S. Nagarajan,J. Mater. Chem. B, 2015, 3, 5560; (c) J. E. P. Sun, B. Stewart, A. Litan, S. J. Lee, J. P.
Schneider, S. A. Langhans and D. J. Pochan,Biomater. Sci., 2016, 4, 839 .

3 (a) S. Sathaye, H. Zhang, C. Sonmez, J. P. Schneider, C. M. MacDermaid, C. D. V. Bargen, J. G. Saven and D. J. Pochan, Biomacromolecules 2014, 15, 3891; (b) W. Liyanage, K. Vats, A. Rajbhandary, D. S. W. Benoit and B. L. Nilsson,Chem. Commun., 2015, 51, 11260; (c) $26 . \quad$ E. R. da Silva, M. N. M Walter, M Reza, V. Castelletto, J. Ruokolainen, C. J. Connon,; W. A. Alves, I. W. Hamley, . Biomacromolecules 2015, 16, 3180.

4 (a) D. K.Maiti, S. Roy, A.Datta and A. Banerjee, Chem. Phys. Lett., 2013,588, 76

5 (a) K. P. Divya, M. Miroshnikov, D. Dutta, P. K. Vemula, P. M Ajayan and G. John, Acc. Chem. Res. 2016, 49, 1671; (b) S. Roy and A. Banerjee, Soft Matter, 2011, 7, 5300.

6 S. Díaz-Oltra, C. Berdugo, J. F. Miravet and B. Escuder, NewJ.Chem., 2015, 39, 3785.

7 D. Yuan, X. Du, J. Shi, N. Zhou, J. Zhou and Bing Xu, Angew. Chem. Int. Ed. 2015, 54, 5705.

8 (a) A. Banerjee, G, Palui and A. Banerjee, Soft Matter, 2008, 4, 1430; (b) W. Liyanage and B. L. Nilsson, Langmuir 2016, 32, 787.

9 P. W. J. M. Frederix, G. G. Scott, Y. M. Abul-Haija, D. Kalafatovic, C. G. Pappas, N. Javid, N. T. Hunt, R. V. Ulijn and T. Tuttle, Nat. Chem., 2015, 7, 30.

10 L. L. Hench and J. K. West, Chem. Rev. 1990, 90, 33.

11 (a) F. Madsen and N. A. Peppas, Biomaterials, 1999, 20, 1701; (b) A. R. Khare and N. A. Peppas, Biomaterials 1995, 16, 559.

12 (a) S.-L. Zhou, S. Matsumoto, H.-D. Tian, H. Yamane, A. Ojida, S. Kiyonaka and I. Hamachi, Chem. Eur. J. 2005, 11, 1130; (b) L. Qin, P.Duan, F.Xie, L. Zhang and M. Liu,Chem. Commun., 2013, 49, 10823; (c) Y. Takashima, S. Hatanaka, M. Otsubo, M. Nakahata, T. Kakuta, A. Hashidzume, H. Yamaguchi and A. Harada, Nature, 2012; (d) F.Xie, L. Qin and M. Liu,Chem. Commun., 2016, 52, 930; (e) M. P. Conte, N. Singh, I. R.Sasselli, B. Escuder and R. V. Ulijn, Chem. Commun., 2016, 52, 13889; (f) L. Qin, F.Xie, X.Jinand M. Liu, Chem. Eur. J. 2015, 21, 11300. 13 Ratna, B. S.Padhi, International Journal of Environmental Sciences, 2012, 3, 940

14 G. Flora, D. Gupta and A. Tiwari,InterdiscipToxicol, 2012, 5, 47.

15 R. M. Brooks, M. Bahadory,F. Tovia, H. Rostami, International Journal of Soil, Sediment and Water, 2010.

16 B. O. Okesola and D. K. Smith,Chem. Soc. Rev., 2016, 45, 4226.

17 (a) F. Li, X. Wang, T. Yuan and R. Sun,J. Mater. Chem. A, 2016, 4, 11888; (b) L. Ling, W.-J. Liu, S. Zhang and H. Jiang,J. Mater. Chem. A, 2016, 4, 10336 